\title{
Evaluation of Pore Structure of Hardened Cement Paste Immersed in Sodium Sulfate Solution
}

\author{
Otsuka Sakata, H. Nicolas ${ }^{1}$, Kennosuke Sato ${ }^{2}$ and Shigehiko Saito ${ }^{2}$ \\ ${ }^{1}$ University of Yamanashi, Faculty of Engineering, Integrated Graduate School of Medicine, \\ Engineering and Agricultural Sciences, 4-3-11, Takeda, Kofu, Yamanashi, 400-8511, Japan, \\ g19tc003@yamanashi.ac.jp \\ ${ }^{2}$ University of Yamanashi, Graduate School of Engineering, Department of Civil Engineering and \\ Environmental Engineering, 4-3-11, Takeda, Kofu, Yamanashi, 400-8511, Japan, \\ satok@yamanashi.ac.jp
}

\begin{abstract}
The purpose of the present study is to evaluate pore structure of hardened cement paste immersed in sodium sulfate solutions and to experimentally examine the relation between the change of pore structure and hydration products. Cement paste specimens were immersed in sodium sulfate solutions and ion-exchanged water for two weeks. Since oxygen gas can pass through the pores having micro scale, it is possible to evaluate the effect of the pore structure on the oxygen transport in cement pastes. Thus, the oxygen diffusion coefficient $\left(D_{\mathrm{O}_{2}}\right)$ of the specimens after immersion were measured, and the pore volume and the pore size distribution were also measured. In addition, the phase compositions of the specimens were acquired. As a result, $D_{O_{2}}$ of the specimens immersed in the sodium sulfate solutions decreased as compared to the specimens immersed in the ion-exchanged water. The tortuosity of the specimens immersed in the sodium sulfate solutions increased due to decreasing of the pore volume having a diameter larger than $20 \mathrm{~nm}$. There was a correlation between the volume of ettringite and the pore volume having a diameter larger than $20 \mathrm{~nm}$. According to the above results, it was considered that the decreasing of $D_{O_{2}}$ in the case of sulfate immersion can occur as a result of the complication of the pore structure owing to filling of the pores by ettringite.
\end{abstract}

Keywords: Sulfate Attack, Oxygen Diffusion Coefficient, Pore Structure, Tortuosity, Ettringite.

\section{Introduction}

The sulfate attack is known as a chemical reaction caused by sulfate and causes the fragility and tissue fragility in hardened cement paste by generating a large amount of ettringite. Although there are not many cases of sulfate deterioration in Japan, there is a high potential risk of sulfate attack in Japan because it is revealed that the marine clay layer producing sulfates is widely distributed (Matsushita et al., 2010). In addition, it is considered that cement-based materials are used for building of radioactive waste processing facilities.

Generally, in order to predict the deterioration phenomenon, it is necessary to grasp the ion transfer characteristics affecting the degradation of hardened cement paste. Furthermore, the ion transfer in the hardened cement paste is known to be greatly affected by the pore structure. Thus, in order to predict the progress of sulfate attack, it is necessary to grasp the pore structure as a transferring field of sulfate ions. However, the pore structure and mass transfer characteristics are significantly changed when the sulfate ions penetrate the hardened cement paste. Sulfate ions causes a reaction with cement hydrate constituting the solid phase and generates ettringite in large quantities, that is considered the cause of change, but there are few 
examples of experimentally examined changes of pore structure and mass transfer characteristics when affected by sulfate attack.

Therefore, we evaluated the oxygen transfer characteristics affected solely by pore structure to clarify the change in the pore structure of the hardened cement paste immersed in sodium sulfate solutions.

\section{Specimens and Methods}

\subsection{Preparation of Specimens}

In this study, ordinary portland cement was used. Table 1 shows the chemical compositions of the cement, and Table 2 shows the density and specific surface area. The mineral compositions calculated by Bogue equation is shown in Table 3. Three types of cement paste specimens having water to cement ratio of $45 \%, 55 \%$ and $65 \%$ were prepared. The size of the specimens was $3 \times 4 \times 0.5 \mathrm{~cm}$. It was demolded at $1 \mathrm{~d}$, and it was wet-sealed curing until $28 \mathrm{~d}$ at $20{ }^{\circ} \mathrm{C}$.
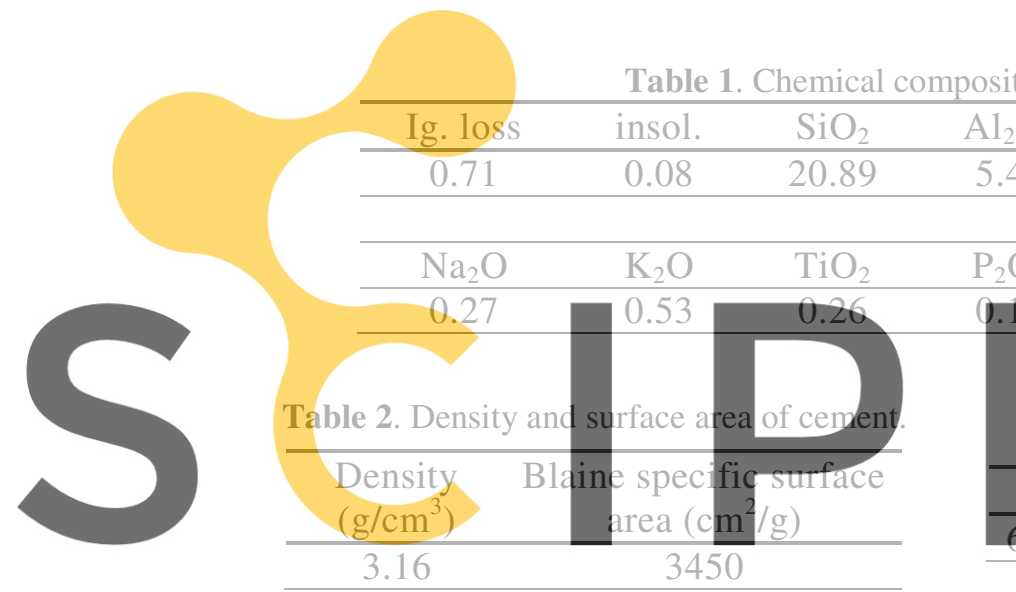

Register for free at https//www.scipedia.com to download the version without the watermark

\subsection{Sodium Sulfate Immersion and Ion-Exchanged Water Immersion}

The specimens were immersed in sulfate solutions. Sodium sulfate and ion-exchanged water (electrical conductivity $0.055 \mu \mathrm{S} / \mathrm{cm}$ ) were used for sulfate solutions. The concentrations of sodium sulfate solutions were 0.5 and 5 mass $\%$. The specimens were immersed in solutions with the liquid-to-solid ratio of 5.0 at $20{ }^{\circ} \mathrm{C}$ for 2 weeks. The specimens were also immersed in the ion-exchanged water for comparison with the case of sodium sulfate immersion.

\subsection{Analysis}

The pore volume of each specimen was measured by Archimedes method. Each specimen after immersion was crushed into small pieces, after which 3 pieces (about $3 \mathrm{~g}$ ) were immersed in ion-exchanged water and reduced pressure for $30 \mathrm{~min}$. The mass of the specimens under water and the mass of the surface-dried condition were subsequently measured. Thereafter, the specimens were dried at $50{ }^{\circ} \mathrm{C}$ in a drying oven until the specimens mass no longer changed. The pore volume was calculated by the following equation (1) 


$$
V=\frac{m_{s}-m_{50 d}}{m_{s}-m_{W}}
$$

where $\mathrm{V}$ is the pore volume $\left(\mathrm{m}^{3} / \mathrm{m}^{3}\right), m_{s}$ is the mass of the surface-dried condition $(\mathrm{g}), m_{50 d}$ is the mass of the dried condition at $50{ }^{\circ} \mathrm{C}(\mathrm{g})$, and $m_{w}$ is the mass of the specimen under water(g).

Pore size distribution was measured by mercury-intrusion-porosimeter. The crushed samples (about $5 \mathrm{~mm}$ ) were immersed in acetone for $2 \mathrm{~d}$ to prevent further hydration. These specimens were subsequently placed under vacuum to remove the acetone and stored in a desiccator in the presence of silica gel until the mass no longer changed. The pressure range was $0.1 \mathrm{kPa}$ to $400 \mathrm{MPa}$. The measurement range of the pore diameter is approximately $4 \mathrm{~nm}$ to 120 $\mu \mathrm{m}$.

Kikuchi et al. (2010) was measured the oxygen diffusion coefficient of the hardened cement paste, which is capable of grasping the complexity of the pore structure. Therefore, in order to grasp the pore structure of the specimens immersed in sodium sulfate solutions, the oxygen diffusion test was performed. The specimens after immersion were dried in a desiccator containing silica gel until the mass no longer changed. The oxygen diffusion test was carried out with reference to the method of Shirakawa et al. (1999). The oxygen concentration was recorded, when the change in oxygen concentration in the nitrogen gas side cell became constant. The oxygen diffusion coefficient was determined using the formula (2)
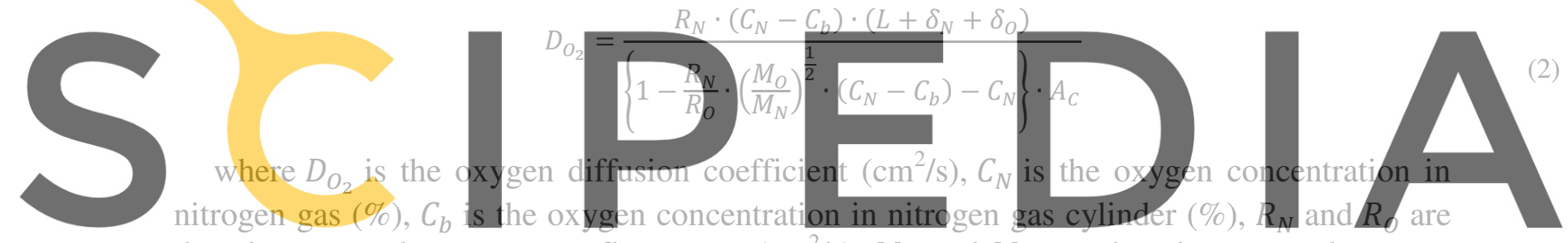

nitrogen gas $(\%), C_{b}$ the nitrogen and oxygen gas flow rates $\left(\mathrm{cm}^{2} / \mathrm{s}\right), M_{N}$ and $M_{O}$ are the nitrogen and oxygen

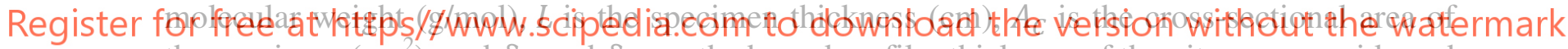
the specimen $\left(\mathrm{cm}^{2}\right)$, and $\delta_{N}$ and $\delta_{O}$ are the boundary film thickness of the nitrogen gas side and oxygen gas side (mm)

Phase composition of the crystal phase of the sample was quantified by XRD / Rietveld analysis. The samples after immersion were immersed in acetone for $2 \mathrm{~d}$ and subsequently placed under vacuum to remove the acetone for $2 \mathrm{~d}$. The samples were crushed and dried at $20{ }^{\circ} \mathrm{C}$ and $11 \% \mathrm{RH}$ until the sample mass no longer changed. In this study, corundum was used as a standard sample, and the amount of the amorphous phase was quantified by the external standard method (Sagawa et al., 2014). The compositions of amorphous phase and $\mathrm{CaO} / \mathrm{SiO}_{2}$ molar ratio of C-S-H (C/S ratio) were calculated by mass balance calculation (Maruyama et al., 2010) using the composition of each hydrate in $11 \%$ RH reported by Suda et al. (2014).

\section{Results and Discussion}

\subsection{Effect of Sodium Sulfate on Oxygen Diffusion Coefficient}

Figure 1 shows the oxygen diffusion coefficient of the sample immersed in sodium sulfate and ion-exchanged water. The oxygen diffusion coefficients of the specimens immersed in sodium 


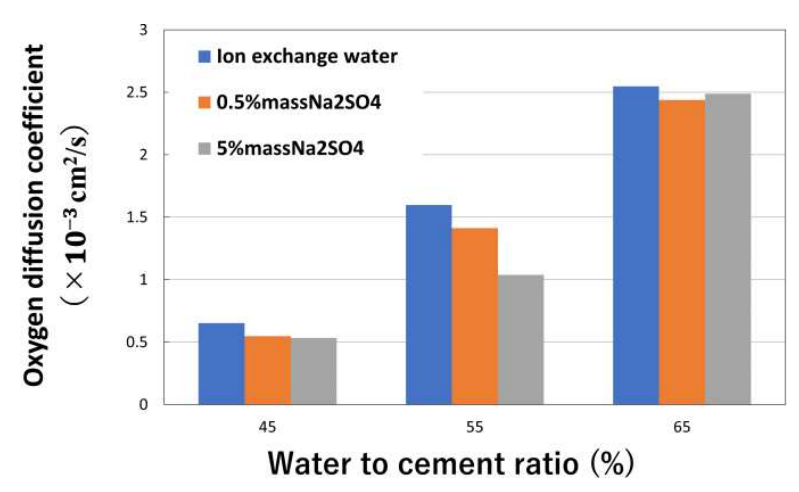

Figure 1. Oxygen diffusion coefficient of hardened cement pastes after immersion.

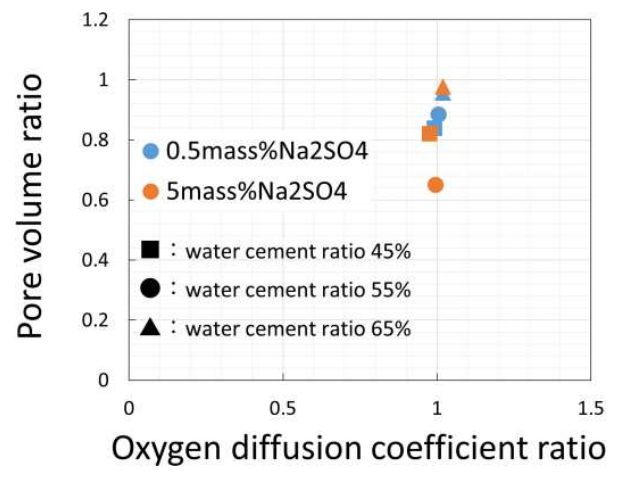

Figure 2. Relationship between oxygen diffusion coefficient ratio and pore volume ratio.

sulfate were reduced regardless of the water-to-cement ratio as compared with the case of ion-exchanged water. However, the degree of decreasing in the oxygen diffusion coefficient varies from water-to-cement ratio. The water-to-cement ratio 55\% is large reduction degree, on the other hand, the degree of decreasing was reduced at the water-to-cement ratio $65 \%$.

\subsection{Change in Pore Structure by the Effects of Sodium Sulfate}

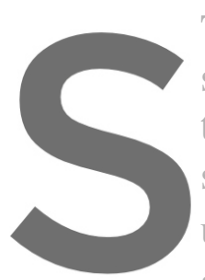

\section{The relationship betw}

sulfate and the change i

the change in the pore

sodium sulfate. The dxy

using the value of the

affected by sodium suifate. Similarly, the pore ratio was calculated.

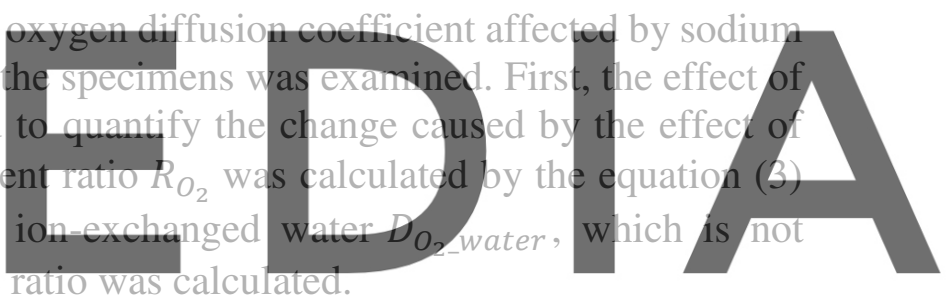

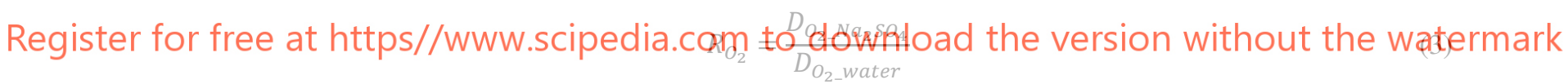

Figure 2 shows the relationship between the oxygen diffusion coefficient ratio and the pore volume ratio. From the figure, the pore volume ratio is almost unchanged at 1.0 while the oxygen diffusion coefficient ratio is greatly changed in the range of 1.0 to 0.6. Thus, the decreasing in the oxygen diffusion coefficient caused by the effect of sodium sulfate could not be explained by a change in the pore volume.

Because it has been reported that the tortuosity is an index representing the complexity of the pore structure (Saeki et al., 2014), the tortuosity of the oxygen diffusion in the hardened cement paste was calculated in this study. The tortuosity of the oxygen diffusion was calculated using the formula (4), with reference to the past studies (Kikuchi et al., 2010; Saeki et al., 2014)

$$
D_{O_{2}}=\frac{1}{\tau_{O_{2}}{ }^{2}} \cdot D
$$

where $\tau_{\mathrm{O}_{2}}$ is the tortuosity of the oxygen diffusion, and $D$ is the effective diffusion coefficient in the pore $\left(\mathrm{cm}^{2} / \mathrm{s}\right)$.

In this study, the parallel pore model was adopted, and the effective diffusion coefficient in the pore was calculated by equation (5) 


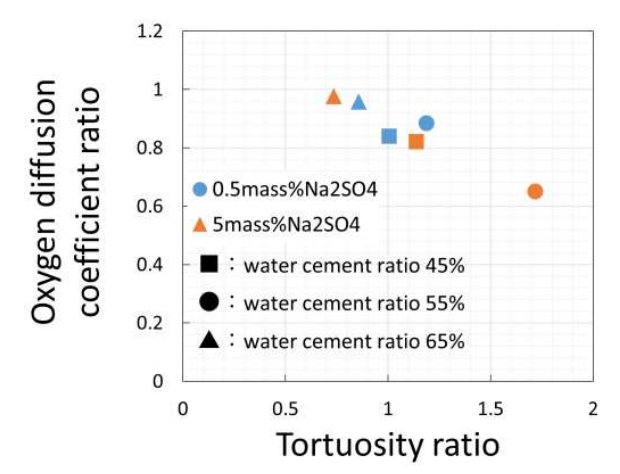

Figure 3. Relationship between oxygen diffusion coefficient ratio and tortuosity ratio.
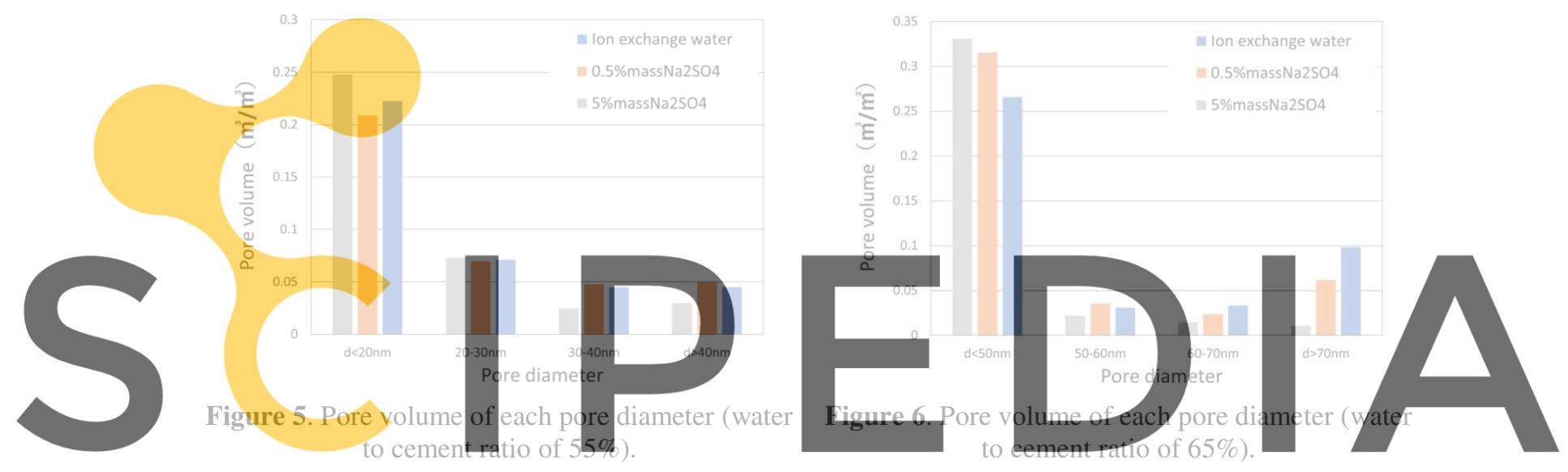

Register for free at https//www.scipedia.com to download the version without the watermark

$$
D=\left(\frac{\varepsilon_{a}}{\frac{1}{D_{K a}}+\frac{1}{D_{O N}}}\right)+\left(\frac{\varepsilon_{b}}{\frac{1}{D_{K b}}+\frac{1}{D_{O N}}}\right)
$$

where $\varepsilon_{a}$ is the pore volume having a diameter $<50 \mathrm{~nm}\left(\mathrm{~cm}^{3} / \mathrm{cm}^{3}\right), \varepsilon_{b}$ is the pore volume having a diameter $>50 \mathrm{~nm}\left(\mathrm{~cm}^{3} / \mathrm{cm}^{3}\right), D_{K a}$ is the Knudsen diffusion coefficient of the average pore diameters $<50 \mathrm{~nm}\left(\mathrm{~cm}^{2} / \mathrm{s}\right), D_{K b}$ is the Knudsen diffusion coefficient of the average pore diameters $>50 \mathrm{~nm}\left(\mathrm{~cm}^{2} / \mathrm{s}\right), D_{O N}$ is the molecular diffusion coefficient of nitrogen and oxygen $\left(\mathrm{cm}^{2} / \mathrm{s}\right)$. The tortuosity ratio was calculated in the same manner as the oxygen diffusion coefficient ratio described above.

Figure 3 shows the relationship between the oxygen diffusion coefficient ratio and the tortuosity ratio. The oxygen diffusion coefficient ratio is reduced with increasing of the tortuosity ratio. These results suggest that the decreasing of the oxygen diffusion characteristics in the hardened cement paste affected sodium sulfate was caused by the increasing of the complexity of the pore structure due to sodium sulfate immersion.

Subsequently, in order to investigate the increasing of the pore structure complexity, we focused on changes in the pore size distribution. Figure 4 to 6 shows the pore volume of each 


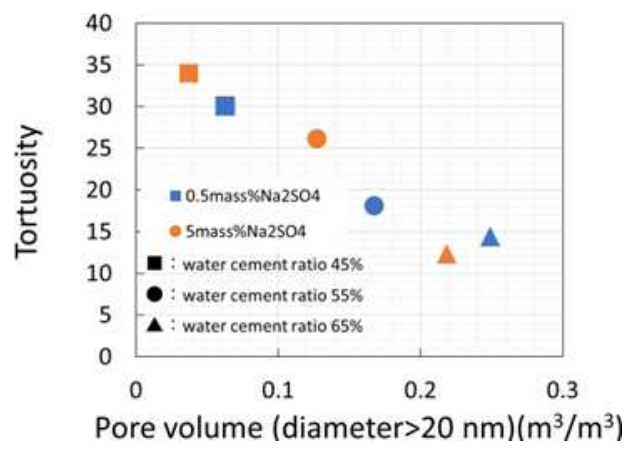

Figure 7. Relationship between tortuosity and pore volume $(\mathrm{d}>20 \mathrm{~nm})$.

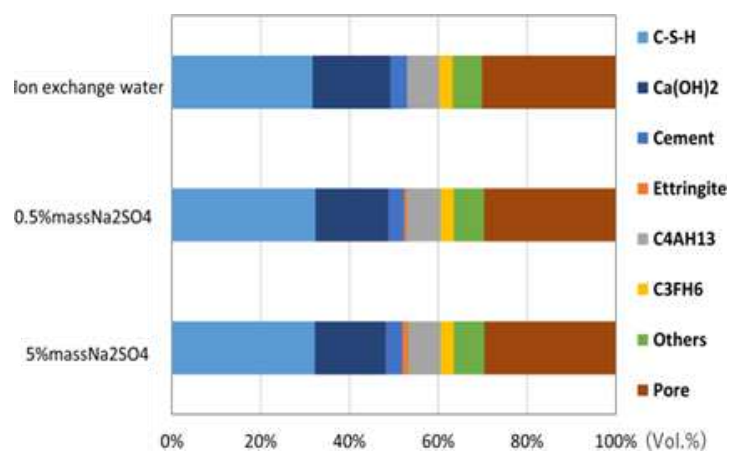

Figure 8. Phase compositions of the specimens after immersion (water-to-cement ratio of $45 \%$ )
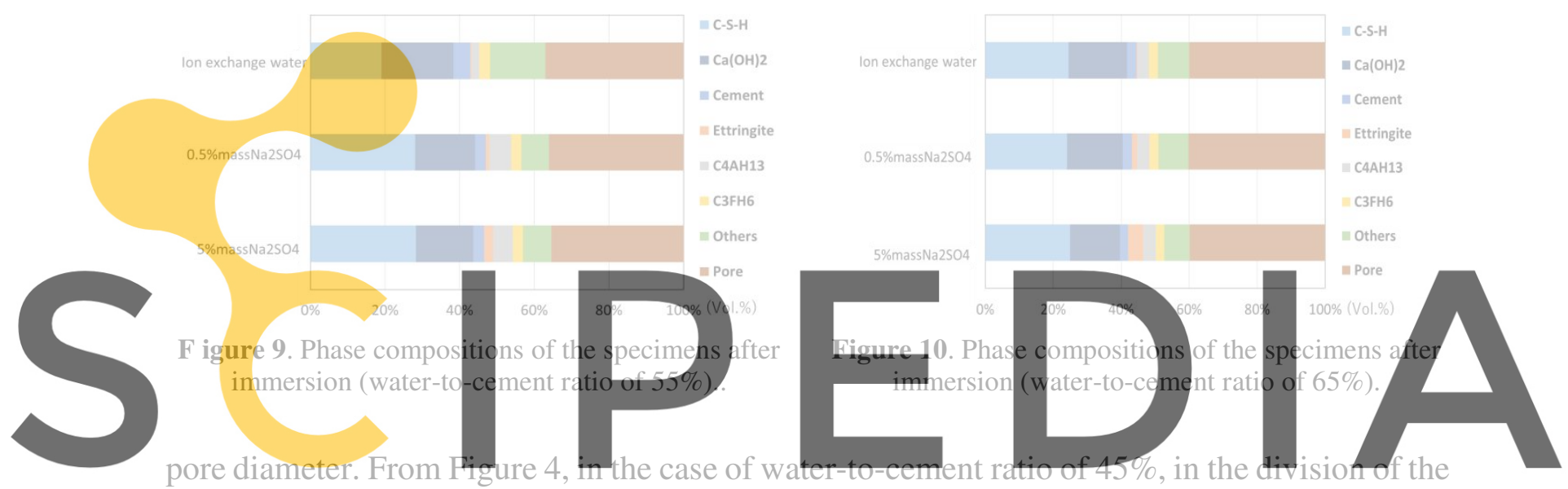

diameter $<20 \mathrm{~nm}$, it was confirmed that the pore volume of the sodium sulfate immersion

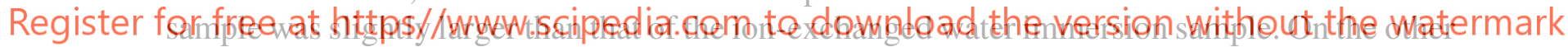

hand, in the division of diameter $>20 \mathrm{~nm}$, the pore volume of the sodium sulfate immersion

sample is reduced as compared to the ion-exchanged water immersion sample. It was confirmed that the diameter of $20 \mathrm{~nm}$ is the boundary of the trend change.

Figure 7 shows the relationship between the tortuosity and the pore volume having a diameter $>20 \mathrm{~nm}$. From the figure, the tortuosity increased with decreasing of the pore volume having a diameter $>20 \mathrm{~nm}$. These results suggest that because the pore volume having a diameter $>20 \mathrm{~nm}$ in the specimen immersed in sodium sulfate decreased, the pore structure was complicated and the oxygen transfer was suppressed.

\subsection{Effect of Hydration Products on the Change of Pore Structure}

Figures 8 to 10 shows the phase compositions of the specimens after immersion having each water-to-cement ratio. In the case of the ion-exchanged water immersion, which is not affected by sodium sulfate, the $\mathrm{C}-\mathrm{S}-\mathrm{H}$ occupies most of the solid phases. In the case of sodium sulfate immersion, the C-S-H also occupies most of the solid phase at any water-to-cement ratio. Furthermore, the higher the water-to-cement ratio and the higher the sodium sulfate concentration, the amount of ettringite was increased. Therefore, we examined the relationship 
between the pore volume having a diameter $>20 \mathrm{~nm}$ and the generation of C-S-H and ettringite.

In order to calculate the volume of $\mathrm{C}-\mathrm{S}-\mathrm{H}$, which is affecting the pore volume, the amount of $\mathrm{C}-\mathrm{S}-\mathrm{H}$ was calculated using equation (6)

$$
M_{C-S-H}=m_{C} \cdot\left(\frac{m_{C-S-H}^{\prime}}{100}\right)
$$

where $M_{C-S-H}$ is the amount of C-S-H per unit volume $\left(\mathrm{g} / \mathrm{m}^{3}\right), m_{C}$ is the amount of cement paste per unit volume $\left(\mathrm{g} / \mathrm{m}^{3}\right), m_{C-S-H}^{\prime}$ is the amount of C-S-H $\left(\mathrm{cm}^{2} / \mathrm{s}\right)$. The volume of C-S-H $V_{I}\left(\mathrm{~m}^{3} / \mathrm{m}^{3}\right)$ was calculated by dividing the $M_{C-S-H}$ by $\rho_{C-S-H}$, which is the density of C-S-H $\left(\mathrm{g} / \mathrm{m}^{3}\right)$ as shown in equation $(7)$.

$$
V_{I}=\left(\frac{M_{C-S-H}}{\rho_{C-S-H}}\right)
$$

Because the density of $\mathrm{C}-\mathrm{S}-\mathrm{H}$ changes depending on the $\mathrm{C} / \mathrm{S}$ ratio, it was calculated from each C/S ratio using the equation (8) of Suda et al. (2014).

$$
\rho_{C-S-H}=0.45(C / S)+1.36
$$

Furthermore, as shown in the equation (9), the volume of C-S-H was calculated

$$
V_{C-S-H}=\frac{V_{I}}{P}
$$

where $V_{C-S-H}$ is the volume of C-S-H $\left(\mathrm{m}^{3} / \mathrm{m}^{3}\right)$, P is the capillary pore volume $\left(\mathrm{m}^{3} / \mathrm{m}^{3}\right)$.

Figure 11 shows the diameter $>20 \mathrm{~nm}$. In both a diameter $>20 \mathrm{~nm}$ dect regression line was drawn for each sodium sulfate solution error between the two lines. Since different linear relationship
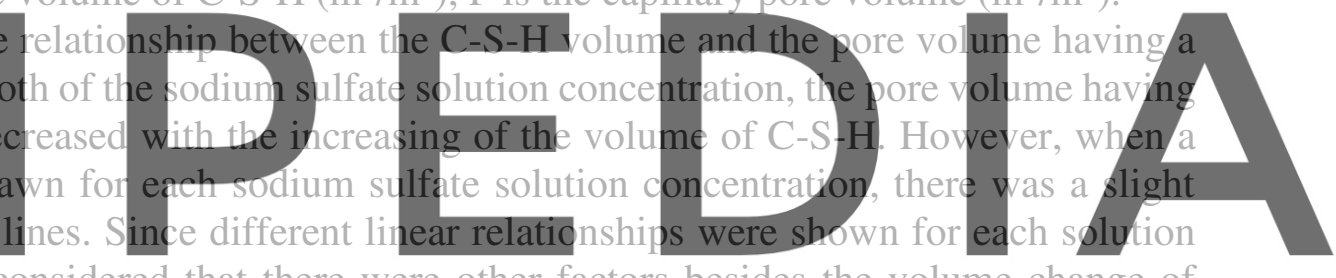

concentration, it was considered that there were other factors besides the volume change of

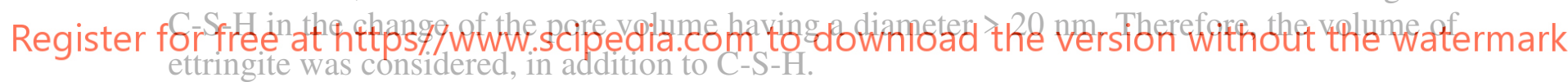

The volume of ettringite $\left(V_{E t t}\right)$ was calculated using the same calculation as in equations (6), (7), and (9). The density of the ettringite was $1.78 \times 10^{6} \mathrm{~g} / \mathrm{m}^{3}$ (Suda et al., 2014). As shown in equation (10), the total volume $\left(V_{C-S-H_{-} E t t}\right)$ was obtained by adding the $V_{E t t}$ to the $V_{C-S-H}$.

$$
V_{C-S-H_{-} E t t}=V_{C-S-H}+V_{E t t}
$$

Figure 12 shows the relationship between the pore volume having a diameter $>20 \mathrm{~nm}$ and the volume of C-S-H and ettringite. In this case, the regression line drawn for each sodium sulfate solution concentration showed almost no error. These results suggest that the decreasing of the oxygen diffusion coefficient of the specimens affected by sodium sulfate was caused by the formation of ettringite, which is filling the pores having a diameter $>20 \mathrm{~nm}$ and the complication of the pore structure.

\section{Conclusions}

The purpose of this study was to investigate the effect of sodium sulfate on the oxygen transfer characteristics and the pore structure of hardened cement paste. The conclusions derived from this study can be summarized as follows. 


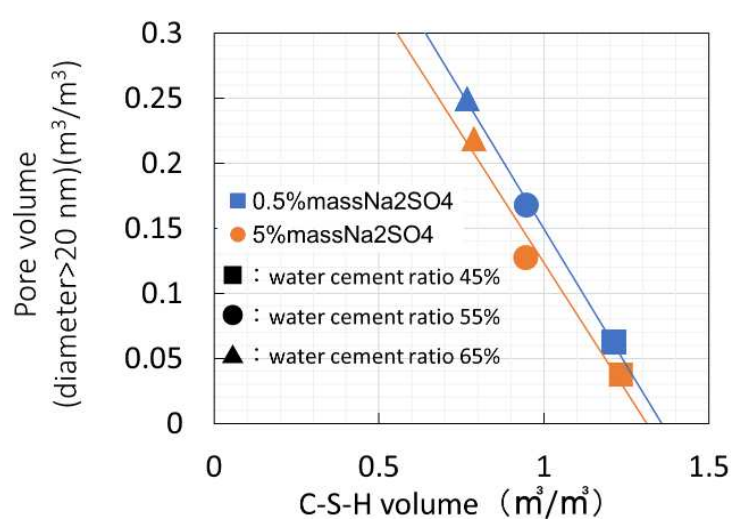

Figure 11. Relationship between pore volume (d > $20 \mathrm{~nm}$ ) and volume of C-S-H.

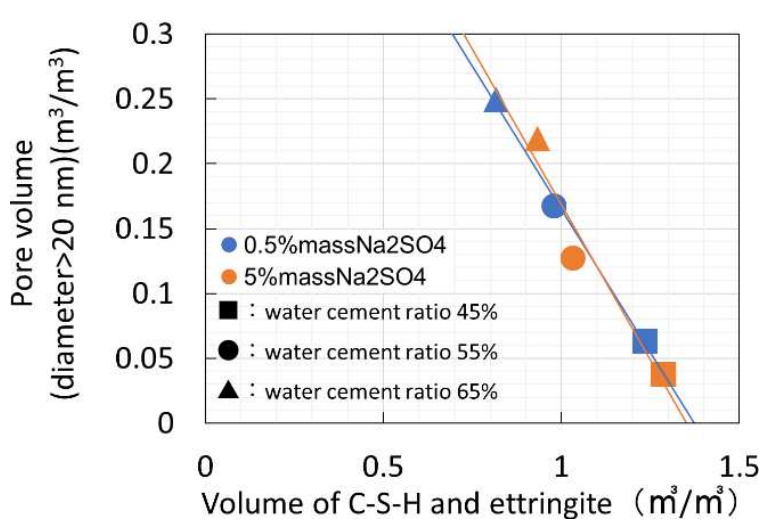

Figure 12. Relationship between pore volume $(\mathrm{d}>$ 20nm) and volume of C-S-H and ettringite.

When the cement paste was affected by sodium sulfate, the oxygen diffusion coefficient decreased compared to the case immersed in ion-exchanged water.

The decreasing of the oxygen diffusion coefficient affected by sodium sulfate was due to the increasing of the tortuosity owing to the decreasing of the pore volume having over $20 \mathrm{~nm}$ in diameter.

The decreasing of the oxygen diffusion coefficient of the specimens affected by sodium

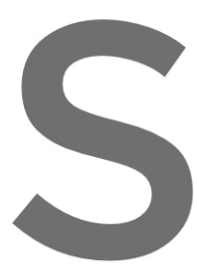
sulfate was caused by the diameter and the complication of

ORCID

Herly Nicolas Otsuka Sakata: https:/orcid.org/0000-0003-0434-9595 Kennosuke Sato: http://orcid.org/0000-0002-3456-4037
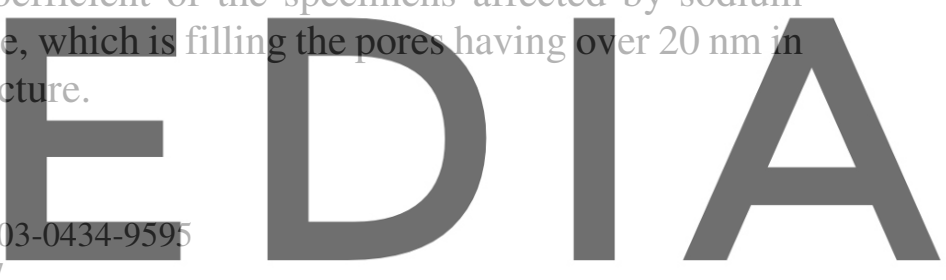

Shigehiko Saito: http://orcid.org/0000-0001-6789-3198

Register for free at https//www.scipedia.com to download the version without the watermark References

Maruyama, I., Matsushita T., Noguchi, Takafumi., Hosokawa, Y. and Yamada, K. (2010). Raie of Hydration of Alite and Belite in Portland Cement -Hydration system of Portland cement Part 1-. J. Struct. Constr. Eng., AIJ. 650, 681-688.

Matsushita, H., Sagawa, Y. and Sato, T. (2010). Classification of probability of deterioration of concrete by sulfate arrack based on investigation results of sulfate content of ground. Journal of Japan Society of Civil Engineers E, 66(4), 507-519.

Kikuchi, M., Suda, Y. and Saeki, T. (2010). Evaluation for Ion Transport in Hardened Cementitious Paste by Oxygen Diffusion and Chloride Diffusion. Cement Science and Concrete Technology, 64 346-353.

Shirakawa, T., Shimazoe, Y., Aso, M., Nagamatsu, S. and Sato, Y. (1999). The Proposal of Testing Method for Determination of Gas Diffusion Coefficient in Hardenend Cement. J. Struct. Constr. Eng., AIJ. 515, 15-21.

Sagawa, T. and Toyoharu, N. (2014). Hydration Analysis and Phase Composition of Cement-based Materials by $X$-Ray Diffraction / Rietveld Method using an External Standard. Cement Science and Concrete Technology, 68, 46-52.

Saeki, T., Mashima K., Kikuchi, M. and Saito, T. (2014). Chroride Ion Diffusivity in Hardended Cementitious Materials using Various Silica Fume. Cement Science and Concrete Technology, 68, 352-359.

Suda, Y., Saeki, T. and Saito, T. (2014). Effect Chemical Composition of $C-S-H$ on Volume and Pore Size Distribution of Gel Pore. (2014). Journal of Japan Society of Civil Engineers E2, 70(2), 134-152. 